\title{
Chairman explains Europe's research council
}

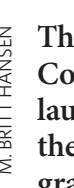

The European Research Council (ERC), to be launched in 2007, will be the first Europe-wide granting agency for basic research. On 5 December, its Scientific Council announced the election of molecular biologist Fotis Kafatos as chairman. Alison Abbott takes this opportunity to quiz

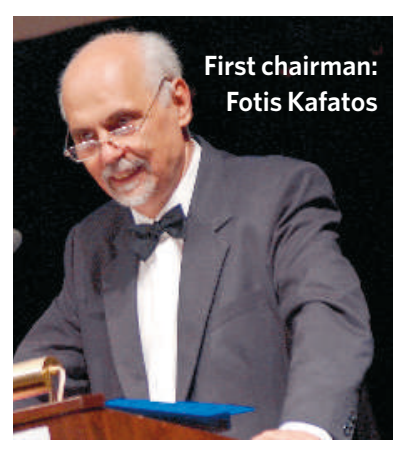

create and supervise an efficient, flexible and responsive structure for our calls for proposals and the peer-review system.

\section{Annual funding of} $€ 1.5$ billion (US\$1.8 billion) has been requested for the ERC, but interest among researchers is so high that huge oversubscription is Kafatos, a lab chief at Imperial College London and formerly director of the European Molecular Biology Laboratory in Heidelberg, Germany.

\section{The ERC is designed to support the best} basic research in Europe based on an independent peer-review system. When will it start distributing money? The political process for approving the seventh of the European Union's five-year Framework programmes for research will run through next year. The Framework's plan to create an ERC is secure, but it will have a legal basis only when this process is completed. We will be using this time for intensive preparatory work, so we should be ready to issue our first call for proposals very soon after that.

\section{What is the role of the Scientific Council} within the ERC structure?

The Scientific Council is the supreme body, and the agency will operate under our guidance. We will be assisted by a secretarygeneral who will have the experience to predicted. How will you structure your calls so as to limit subscriptions? The ERC will cover all fields of scholarship. One of our key tasks is to work out how to structure calls in a way that does not compromise this basic tenet. At the moment, no option is excluded. We will also think about a two-stage application procedure to relieve oversubscription.

\section{How will the ERC peer-review system operate?}

This is also something that we have to work out in detail. Certainly, it will take into account the international best practice.

\section{What would happen if the Framework} programme were to be squeezed hard during political negotiations, and the ERC given less money than requested? It would not be worth establishing the ERC if it were poorly endowed - the funding has to be sufficient for it to work properly and make a difference. Personally, I think the absolute minimum would be $€ 1$ billion per year.

\section{IMAGE} UNAVAILABLE FOR COPYRIGHT REASONS
DNA barcoding identifies well known species such as this chestnut cowrie, but it comes a cropper on others. says David Schindel, executive secretary of the Consortium for the Barcode of Life, a group of 93 barcoding practitioners hosted by the Smithsonian Institution in Washington DC. "Chris and
Gustav have done a very good job of presenting the possible procedural problems that barcoding will encounter, and we are working out protocols for more sophisticated analysis of barcode data," says Schindel. Meyer stresses that the concept of barcoding remains solid. Indeed, his museum is a member of the barcoding consortium. But, he says, his study shows that barcoding will not supplant traditional taxonomy. Meyer says he hopes his study will help convince funding agencies to support old-fashioned taxonomy - a discipline that seems to be slowly disappearing - as well as DNA barcoding. Erika Check 